\title{
The Study of Grading Method and Application Performance of Management Systems of Rural Potable Water Treatment Plants
}

\author{
Xinkai QIU ${ }^{\mathrm{a}}$, Cheng LU ${ }^{\mathrm{a}, 1}$, Yinying $\mathrm{ZHOU}^{\mathrm{b}}$, Shuyang $\mathrm{CHEN}^{\mathrm{c}}$ \\ ${ }^{a}$ Zhejiang Institute of Hydraulics and Estuary (Zhejiang Institute of Marine Planning \\ and Design), Hangzhou 310020, China \\ ${ }^{b}$ Division of Hangzhou West Lake Aquatic Area Management, Hangzhou 310002, China \\ ${ }^{c}$ Hangzhou Dingchuan Information Technology Co., Ltd, Hangzhou 310016, China
}

\begin{abstract}
The application of management systems can solve the manage problems and improve the potable water safety for rural potable water treatment plants. The systems in Zhejiang province, China are studied and the system grading method is proposed as attendance management $\left(G_{1}\right)$, basic automatic management $\left(G_{2}\right)$, quantity-based automatic management $\left(G_{3}\right)$, quality-based intelligent management $\left(G_{4}\right)$, quality-based \& feedback controlled intelligent management $\left(G_{5}\right)$. $G 3$ to $G 5$ systems can achieve remote control and $G 4, G 5$ systems can guarantee the finished water quality theoretically. The application performance of the management systems shows $G_{5}$ system has the lowest allocated annual cost as 11500 RMB per year when used to service life as 5 years $\left(23.37 \%\right.$ of $G_{1}$ system). By using $G_{5}$ system, the finished water turbidity is below $0.8 \mathrm{NTU}, \mathrm{pH}$ is between 7.6 to 8.2 , and the qualification rate of residual chlorine is above $92.5 \%$, which performances better than $G_{3}$ system with finished water turbidity below $9.7 \mathrm{NTU}$, pH between 7.3 to 8.2, and the qualification rate of residual chlorine above $88.7 \%$. $G_{5}$ system is recommended when the plant is hard to be staffed or the inlet water quality is not good. $G_{3}$ system is recommended when the inlet water quality is good or the purchase budget is limited.
\end{abstract}

Keywords. Rural potable water treatment plant, management system, grading method, application performance

\section{Introduction}

The rural potable water treatment plants have to face the manage problems like inadequate equipment maintenance and operators without enough water treatment knowledge[1]. For instance, there were above 9000 villages supplied by rural potable water treatment plants in year 2020 in Zhejiang province, China. It is hard to manage all

\footnotetext{
${ }^{1}$ Corresponding Author: Cheng Lu, Zhejiang Institute of Hydraulics and Estuary (Zhejiang Institute of Marine Planning and Design), Hangzhou 310020, China; E-mail: 1c1001cn@163.com

This work was financially supported by National Key Research and Development Program of China (No. 2019YFC0408801).
} 
the rural plants by human management adequately, and some researches have found rural plants do not have enough managers and one has to take on multiple duties [2].

Using the management systems to replace human managers is an important method to solve the problems and improve the potable water safety. Different management systems have been applied in some plants to monitor the key process of water treatment and make warning [3]. Even more, the computational intelligence has been used in some plants to predict the chemical dosage with good result, instead of the decisions carried out by human experience [4]. There is a necessity to make a comparison study of different management systems, but the previous researches focused more on the performance of a single management system and their grade was not classified. This paper put forward a grading method of the management systems of rural potable water treatment plants. And the application performance of different grades of management systems was analyzed and compared to conduct the application recommendations.

\section{Materials and Methods}

\subsection{Plants With Graded Management Systems}

Different management systems used in rural potable water treatment plants in Zhejiang province were studied to put forward the grading method and to analyze their application performance.

The study of cost performance is based on the plants covered all the grade of management systems. The purchase cost and running cost of the systems were collected and analyzed.

The study of water quality performance is based on three plants with daily supply capacities of 15 tons (PLANT15), 100 tons (PLANT100) and 600 tons (PLANT100). These plants had upgraded the management systems from the grade that cannot guarantee the water quality to the highest grade.

\subsection{The Analytical Method of Management System Grades}

The intelligent systems can judge if the water treatment performance is satisfied and take actions to correct, which is based on monitors, on-line data and lab measures [5], so the equipment and data transmission mode for the systems were analyze in this study. However, the labs were excluded because a great quantity of plants in Zhejiang province do not have it or use water quality monitors for instead.

The equipment can be classified as three types. The first is traditional monitor equipment like camera, alarm and data collection terminal. The second is control equipment like float switch, electromagnetic valve and chemical dosing equipment. The third is detectors and feedback equipment, including programmable logic controller (PLC) and monitors for flow, pressure and water quality.

The data transmission can be classified as two modes. The first use SIM card with $2 \mathrm{G}$ or $4 \mathrm{G}$ internet to transmit pictures or videos and help monitoring the attendance of managers. The second use cable network to transmit data and command stably, which can achieve remote control. 
The combination of equipment and transmission mode can achieve different management functions. and the management system grades can be classified by the functions.

\subsection{The Analytical Method of Application Performance}

The application performance includes costs and finished water quality of different management systems.

The cost analysis is based on the purchase cost of management equipment and running cost of labor and materials incurred for the systems. The systems studied with different grades have the same designed serviceable life as 5 years, and the purchase and running cost were separated into the service period to calculate the allocated annual cost.

Total coliforms, turbidity and $\mathrm{pH}$ have the highest ineligible rate in finished water of rural potable water treatment plants in Zhejiang province [6], which are most concerned and used to represent the water treatment performance. Therefore, the data of residual chlorine, turbidity and $\mathrm{pH}$ was collected by water quality monitors and analyzed in this study. The finished water quality is compared with the Standards for Drinking Water Quality of China (GB 5749-2006) to judge if it is qualified [7]. Also, the inlet water with low turbidity (below 10 to $30 \mathrm{NTU}$ ) [8] is hard to treat. This study analyzed the inlet water turbidity below or above 15 NTU separately, if the data is monitored in a large range.

\section{Results and Discussion}

\subsection{The Grading Method of Management Systems}

Depends on the equipment and data transmission mode, the functions of the management systems can be classified into five grades.

The first and least intelligent grade is attendance management. By equipping camera and transmit data with SIM card, the plant can capture the pictures to record the attendance and alarm the managers.

The second grade is basic automatic management. By equipping automatic control equipment and transmit data with SIM card, the plant can automatic start or stop. For example, when the water in clean water basin is enough, the floating switch will cut off water produce [9].

The third grade is quantity-based automatic management. By equipping automatic control equipment, inlet flow monitor and PLC, the plant can change the chemical dosage to fit the inlet flow [10]. From this grade and higher grades, the plants can be remote controlled with cable network.

The fourth grade is quality-based intelligent management. By adding pressure monitors and finished water quality monitors over the third grade. The plant can increase the chemical dosage to make the finished water turbidity back to be qualified, and backwash intelligently to decrease the pressure difference from inlet and finished water. However, this system cannot retrace the increased chemical dosage settings when the inlet water quality gets better or the finished water gets easier to be qualified.

The fifth and most intelligent grade is quality-based \& feedback controlled intelligent management. By adding inlet water quality monitors over the fourth grade, 
the plant can adjust the treatment settings by monitoring the water quality, and also retrace it when the inlet water quality has a better feedback.

Depending on the functions, the grading method can be set as five levels given in table $1 . G_{1}$ to $G_{3}$ systems are unable to monitor or deal with the change of water quality, so the finished water qualities for these three grades are not guaranteed theoretically.

Table 1. The grading method of management systems for rural potable water treatment plants.

\begin{tabular}{|c|c|c|c|c|}
\hline Grades & Management functions & Management contents & $\begin{array}{l}\text { Control } \\
\text { methods }\end{array}$ & $\begin{array}{l}\text { Finished } \\
\text { water quality }\end{array}$ \\
\hline$G_{1}$ & Attendance management & All contents & \multirow{2}{*}{$\begin{array}{l}\text { Field } \\
\text { management }\end{array}$} & \multirow{3}{*}{$\begin{array}{l}\text { Quality not } \\
\text { guaranteed }\end{array}$} \\
\hline$G_{2}$ & Basic automatic management & $\begin{array}{l}\text { Chemical replenish, } \\
\text { dosage adjustment }\end{array}$ & & \\
\hline$G_{3}$ & Quantity-based automatic management & Chemical replenish, & \multirow{3}{*}{$\begin{array}{l}\text { Remote } \\
\text { management }\end{array}$} & \\
\hline$G_{4}$ & Quality-based intelligent management & dosage adjustment & & \multirow{2}{*}{$\begin{array}{l}\text { Quality } \\
\text { guaranteed }\end{array}$} \\
\hline$G_{5}$ & $\begin{array}{l}\text { Quality-based \& feedback controlled } \\
\text { intelligent management }\end{array}$ & Chemical replenish & & \\
\hline
\end{tabular}

\subsection{The Application Cost of Management Systems}

The equipment and the cost are given in table 2. The running cost is given in table 3 . In the locality, the personnel cost for field manager is $2000 \mathrm{RMB} \cdot \mathrm{month}^{-1}$ for $G_{1}$ system and half for $G_{2}$ system. The personnel cost for engineer to adjust the chemical dosage is $2000 \mathrm{RMB} \cdot \mathrm{month}^{-1} \cdot \mathrm{plant}^{-1}$. The system with residual chlorine monitors need 260 $\mathrm{RMB} \cdot \mathrm{month}^{-1}$ for the replacement of detection reagent.

Table 2. The purchase cost of management systems.

\begin{tabular}{llll}
\hline Grades & Controlling equipment and monitor equipment & Others & Cost (RMB) \\
\hline$G_{1}$ & Data collection terminal & Camera & 30000 \\
$G_{2}$ & $\begin{array}{l}\text { Flow switch, float switch, electromagnetic valve, } \\
\text { electromagnetic relay, chemical dosing equipment }\end{array}$ & Video camera & 80000 \\
$G_{3}$ & $G 2$ system adding PLC, Inlet flow monitor & & 120000 \\
$G_{4}$ & $\begin{array}{l}G 3 \text { system adding pressure monitor, finished water quality } \\
G_{5}\end{array} \quad \begin{array}{l}\text { monitor (turbidity, pH, residual chlorine) camera, } \\
\text { intruder alarm, }\end{array}$ 170000 \\
\hline
\end{tabular}

Table 3. The running cost of intelligent management systems.

\begin{tabular}{llllll}
\hline Grades & Manpower demand & $\begin{array}{l}\text { Personnel cost } \\
\left(\mathrm{RMB} \cdot \mathrm{month}^{-1}\right)\end{array}$ & $\begin{array}{l}\text { Material } \\
\left(\mathrm{RMB} \cdot \mathrm{month}^{-1}\right)\end{array}$ & $\begin{array}{l}\text { cost } \\
\left(\mathrm{RMB} \cdot \mathrm{year}^{-1}\right)\end{array}$ & $\begin{array}{l}\text { Running } \\
\text { cost }\end{array}$ \\
\hline$G_{1}$ & Field manager \& Engineer & 4000 & $/$ & 48000 \\
$G_{2}$ & Field manager \& Engineer & 3000 & $/$ & 36000 \\
$G_{3}$ & Engineer & 2000 & $/$ & 24000 \\
$G_{4}$ & Engineer & 2000 & 260 & 27120 \\
$G_{5}$ & $/$ & $/$ & 260 & 3120 \\
\hline
\end{tabular}

$G_{4}$ system can guarantee the finished water quality but still needs engineer to adjust chemical dosage settings, and have extra cost for detection reagent, so its running cost is higher than $G_{3}$ system. Other grade of systems has lower running cost than the lower grades. After allocating the purchase cost into the service period happened, the allocated annual cost is given in figure1, which shows $G_{3}$ system has the lowest cost when used for 2 years, and $G_{5}$ system has it when used for 3 and more years.

\subsection{The Finished Water Quality Performance of Management Systems}

Because $G_{1}$ to $G_{3}$ systems cannot guarantee the finished water quality, the water qualities with $G_{3}$ and $G_{5}$ from three plants were analyzed to show the enhance of water quality by the upgrade of management systems. 


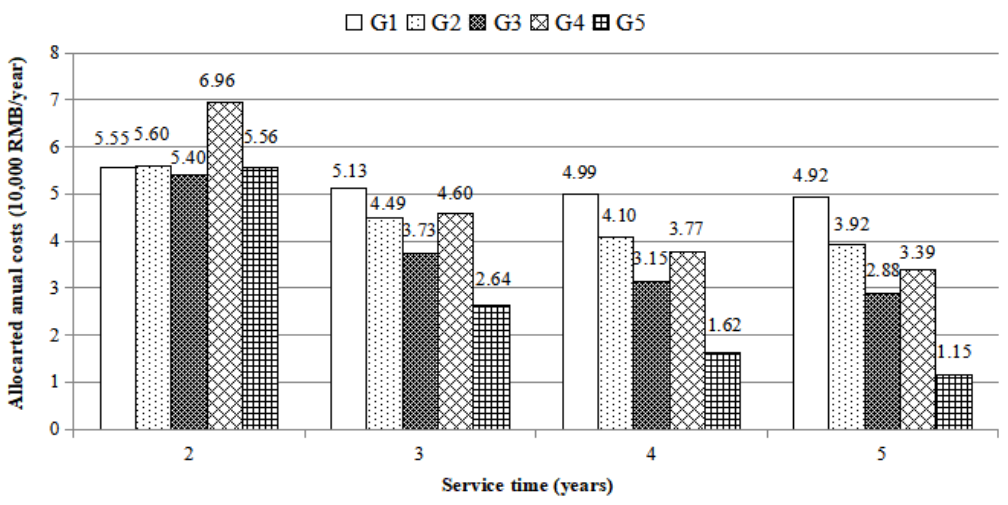

Figure 1. The allocated annual costs of management systems.

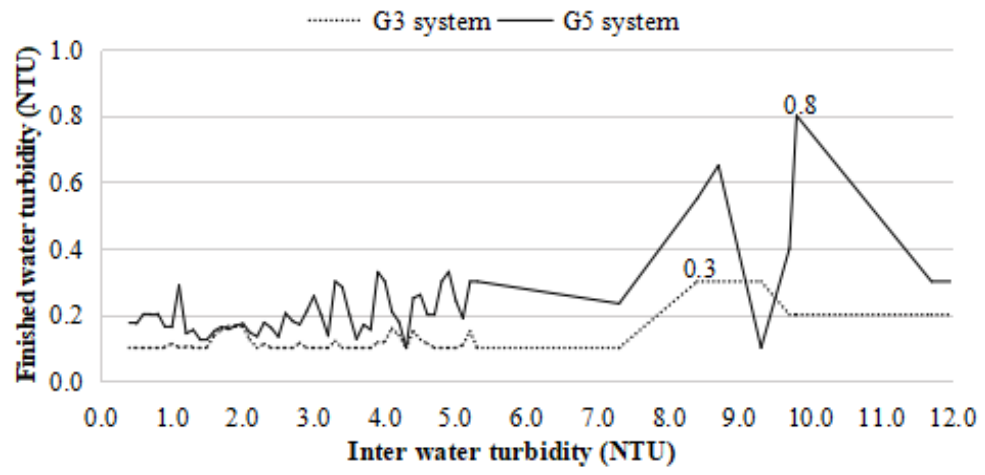

(a) PLANT15

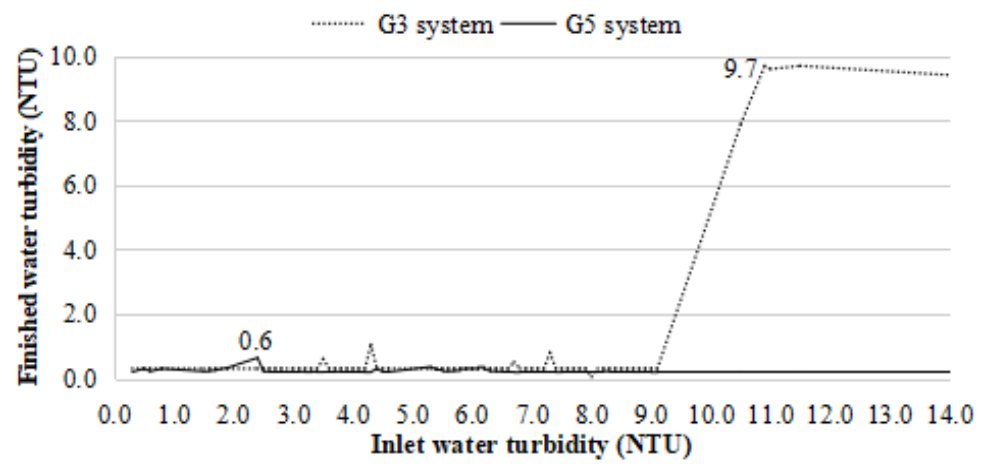

(b) PLANT600 

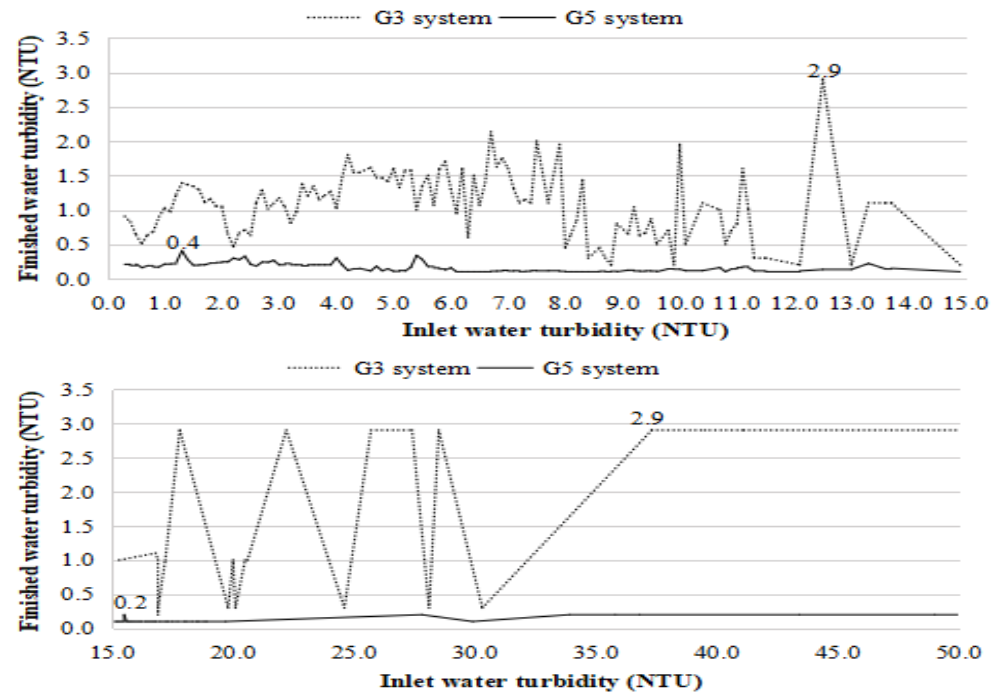

(c) PLANT100

Figure 2. The water turbidity with $G_{3} \& G_{5}$ systems.

\subsubsection{Turbidity}

The inlet and finished water turbidity for three plants are given in figure 2. It shows $P L A N T 15$ has lower inlet water turbidity and $G_{5}$ system does not show any improvement. PLANT100 and PLANT600 with $G_{5}$ systems have lower finished water turbidity than those with $G_{3}$ systems. It should be noticed that when the inlet water turbidity is higher than 9 NTU in PLANY600, $G_{3}$ system is unable to monitor it or change water treatment settings, so its finished water turbidity can not meet the standard (below 3 NTU).

\subsection{2. $\mathrm{pH}$}

The inlet and finished water $\mathrm{pH}$ for three plants are given in figure 3 . It shows all the finished water $\mathrm{pH}$ with $G_{3}$ or $G_{5}$ systems can meet the standard (between 6.5 to 8.5). PLANT15 has a stable inlet water $\mathrm{pH}$, and $G_{5}$ system does not show any enhance. PLANT100 and PLANT600 with $G_{5}$ systems has more stable finished water $\mathrm{pH}$ than those with $G_{3}$ systems.

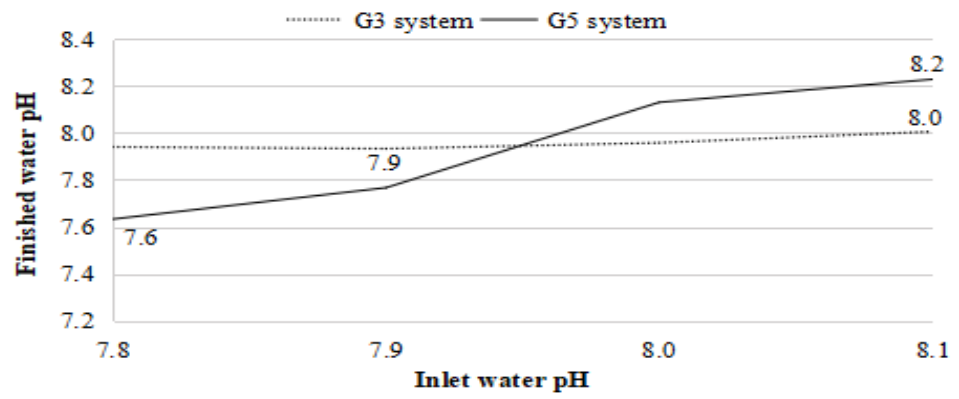

(a) PLANT15 


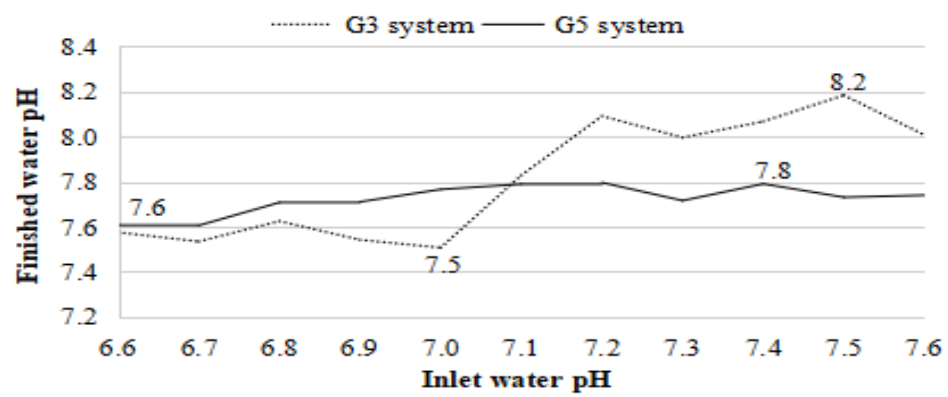

(b) PLANT100

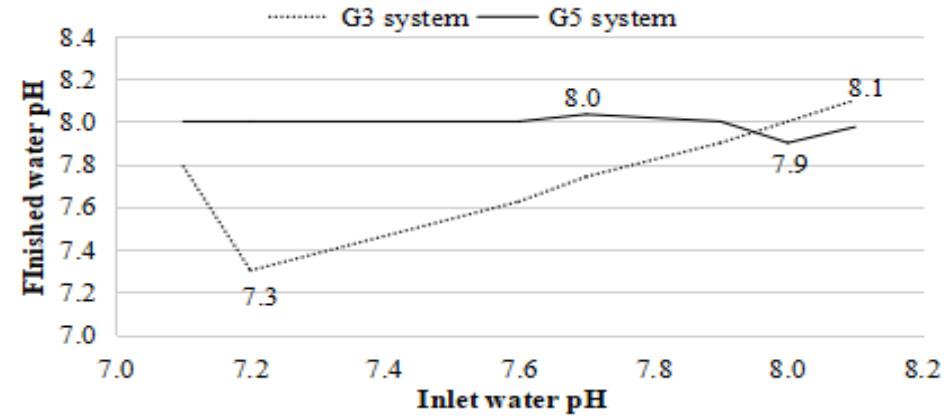

(c) PLANT600

Figure 3. The treatment performance of $\mathrm{pH}$ with $G_{3} \& G_{5}$ management systems.

\subsubsection{Residual Chlorine}

The finished water residual chlorine for three plants are given in table 4. It shows the residual chlorine qualification rates with $G_{5}$ systems are higher than those with $G_{3}$ systems. Especially for small plants like PLANY15 with $G_{3}$ system, its chemical dosage is based on manual settings and hard to meet the standard.

The average residual chlorine with $G_{3}$ system is $1.1 \mathrm{mg} \cdot \mathrm{L}^{-1}$, while it is more stable and approaching the standard value $\left(0.3 \mathrm{mg} \cdot \mathrm{L}^{-1}\right)$ with $G_{5}$ system. The finished water having lower and qualified residual chlorine with $G_{5}$ system is more acceptable for rural water users.

Table 4. The treatment performance of residual chlorine with $G_{3} \& G_{5}$ management systems.

\begin{tabular}{lllll}
\hline \multirow{2}{*}{ Plants } & \multicolumn{2}{l}{ Residual chlorine with $G 3$ system } & \multicolumn{2}{l}{ Residual chlorine with $G 5$ system } \\
\cline { 2 - 5 } & Average $\left(\mathrm{mg} \cdot \mathrm{L}^{-1}\right)$ & Qualification rate $(\%)$ & Average $\left(\mathrm{mg} \cdot \mathrm{L}^{-1}\right)$ & Qualification rate $(\%)$ \\
\hline PLANT15 & 1.1 & 88.7 & 0.3 & 92.5 \\
PLANT100 & 0.4 & 94.3 & 0.4 & 97.8 \\
PLANT600 & 0.7 & 97.1 & 0.6 & 98.9 \\
\hline
\end{tabular}

\section{Conclusions}

The management systems for rural potable water treatment plants can be graded as attendance management $\left(G_{1}\right)$, basic automatic management $\left(G_{2}\right)$, quantity-based automatic management $\left(G_{3}\right)$, quality-based intelligent management $\left(G_{4}\right)$, quality-based \& 
feedback controlled intelligent management $\left(G_{5}\right) . G_{3}$ to $G_{5}$ systems can realize remote control, $G_{4}$ and $G_{5}$ systems can guarantee the finished water quality.

$G_{5}$ system has the lowest allocated annual cost as 11500 RMB per year $(23.37 \%$ of $G_{1}$ system) when used for 3 and more years. $G_{3}$ system has only $57.14 \%$ of the purchase cost of $G_{5}$ system, and has the lowest allocated annual cost as 54000 RMB per year ( $77.59 \%$ of $G_{4}$ system) when used for 2 years.

$G_{5}$ system can improve the performance of finished water quality. The finished water turbidity is all qualified and below $0.8 \mathrm{NTU}$ with $G_{5}$ system, while it is not all qualified and below 9.7 NTU with $G_{3}$ system. The finished water $\mathrm{pH}$ is between 7.6 to 8.2 with $G_{5}$ system., while it has a wider deviation between 7.3 to 8.2 with $G_{3}$ system. The qualification rate of residual chlorine is above $92.5 \%$ with $G_{5}$ system, while it is only above $88.7 \%$ with $G_{3}$ system. $G_{3}$ system may has better finished water quality if the inlet water quality is good and stable, take this study as example, the inlet water turbidity is below $12 \mathrm{NTU}$ and $\mathrm{pH}$ is stable from 7.9 to 8.0.

$G_{5}$ system is recommended when the plant has no manager, the inlet water quality is limited and the finished water quality is highly demanded. $G_{3}$ system is recommended when the inlet water quality is good, the purchase budget is limited.

\section{References}

[1] Momba MNB, Tyafa Z, Makala N. Rural water treatment plants fall to provide potable water to their consumers: the Alice water treatment plant in the Eastern Cape province of South Africa. J. Sci. 2004; 100(5-6):307-310.

[2] Wu XM, Sun QS, Shan J. Research on Post Arrangement and Fixed Number of Persons of Rural Water Supply Enterprise. China Rural Water and Hydropower. 2014; 1:61-63.

[3] Wu J, Hao XW, Yang CJ. Programming and Application of Online Monitoring and Warning System for Rural Drinking Water. Zhejiang Hydrotechnics. 2013; 41(3):1-3.

[4] Fabio CRS, André FHL, Cleber G Dias, et al. Intelligent system for improving dosage control. Acta Scientiarum: Technology. 2017; 39(1):33-38.

[5] Dan S, Gopal A, Cooper HL, et al. Performance management of small water treatment plant operations: a decision support system. Water and Environment Journal. 2017; 31(3):330-344.

[6] Ren BZ, Deng RJ. Safety of Rural Drinking Water and Its Counter measures. China Safety Science Journal. 2008; 5:11-17.

[7] He XJ, Wang B, Qiu C, et al. Water quality investigation and analysis for rural drinking water in Zhejiang Province China. Water Resources. 2019; 11:40-42.

[8] Zhao XD. Treatment of Low Temperature and Low Turbidity Water. Journal of Shanghai University of Electric Power. 2009; 25(05):487-490.

[9] Li JH. Design and application of remote monitoring system for centralized water supply. Modern Electronics Technique. 2013; 17: 96-97.

[10] MO RB. Analysis and Solution for Water Quality Problems in Rural Water Supply Project. Water Purification Technology. 2021; 40(1):146-149. 